\title{
ANALISIS KEAUSAN DISC DENGAN MATERIAL BAJA ST 70 MENGGUNAKAN ALAT TRIBOTESTER PIN-ON-DISC DENGAN VARIASI PELUMASAN
}

\author{
Imam Yudi Amami*, Darmanto, Imam Syafa'at \\ Jurusan Teknik Mesin Fakultas Teknik Universitas Wahid Hasyim Semarang \\ Jl. Menoreh Tengah X/22, Sampangan Semarang 50236 \\ *Email : imamy987@gmail.com
}

\begin{abstract}
Abstrak
Pin-on-disc merupakan salah satu komponen dari tribotester yang berfungsi untuk menguji tingkat keausan dan gesekan dari suatu material. Penelitian ini bertujuan untuk mengetahui tingkat volume keausan dari disc dengan menggunakan variasi kondisi pelumasan. Material yang digunakan pada pengujian adalah material baja jenis karbon rendah yaitu : Baja ST 70. Sedangkan variasi pelumas yang digunakan pada penelitian ini adalah tanpa pelumasan, pelumas SAE 40, SAE 90 dan SAE 140. Pada penelitian ini menunjukkan volume keausan tertinggi terletak pada pengujian tanpa pelumas yaitu $23,1521 \mathrm{~mm}^{3}$ dengan panjang jarak tempuh 1,1684 km, sedangkan kondisi pelumasan volume keausan yang terjadi pada disc mengalami perubahan, hal ini disebabkan karena pin dan disc di separasi/dilapisi lapisan film. Sedangkan faktor keausan disc tanpa pelumas adalah 8,1159E-10 mm $\mathrm{mm}^{3} \mathrm{~N} . \mathrm{mm}$, sedangkan nilai faktor keausan pada masing-masing kondisi pelumasan SAE 40, SAE 90 dan SAE 140 adalah 5,0897E-10 mm³. $\mathrm{mm}^{3} / \mathrm{N} . \mathrm{mm}$.
\end{abstract}

Kata kunci : keausan disc, pin-on-disc, variasi pelumasan

\section{PENDAHULUAN}

Sejalan semakin tingginya ilmu pengetahuan dan teknologi yang lebih modern, dalam dunia permesinan banyak faktor yang mempengaruhi umur pemakaian dari sebuah mesin, misalnya kualitas komponen, cara pemakaian dan perawatannya. Permasalahan yang terjadi setiap komponen mesin bisa berupa static contact, rolling contact ataupun sliding contact. Merupakan hal yang penting, karena dapat mempelajari bagaimana struktur topografi permukaan (asperity) mengalami deformasi (Armanto dkk., 2012).

Keausan (wear) adalah hilangnya materi dari permukaan benda padat sebagai akibat dari gerakan mekanik. Keausan umumnya sebagai kehilangan materi yang timbul akibat interaksi mekanik dua permukaan yang bergerak sliding dan dibebani. Ini merupakan fenomena normal yang terjadi jika dua permukaan saling bergesekan, maka akan ada keausan atau perpindahan materi. Keausan dapat dipengaruhi oleh faktor pembebanan, pelumasan, panjang lintasan, dan sifat dari material tersebut (Firmansyah, 2010).

Maka dari itu dapat disimpulkan bahwa keausan dapat dikendalikan, sehingga faktor faktor yang menyebabkan kegagalan dapat ditanggulangi dengan baik. Salah satu faktor yang berguna mengurangi gesekan antar part adalah dengan diberi pelumas.

Pelumasan adalah tindakan menempatkan pelumas antara permukaan yang saling bergeser untuk mengurangi keausan dan friksi. Friksi sendiri adalah gaya yang menahan gerakan sliding atau rolling satu benda terhadap benda lainnya. Friksi merupakan faktor yang penting dalam mekanisme operasi sebagian besar peralatan atau mesin. (Firmansyah, 2010).

Tribotester adalah perangkat yang digunakan untuk mengukur gesekan dan keausan antara dua permukaan. Alat Tribotester pin-on-disc adalah alat uji gesek dan keausan yang terdiri dari pin dan disc. Pin memiliki berbagai bentuk dan ukuran, umumnya berbentuk bola atau bentuk silinder batang, sedangkan disc atau piringan dengan tebal tertentu berbentuk plat berdiameter. Penggunaan mesin pin-on-disc biasanya digunakan untuk menguji keausan jenis sliding dan rolling (Prabowo dkk., 2012).

Dalam penelitian ini yang dilaksanakan menggunakan variasi pelumas yang berfungsi untuk memperkecil gesekan dan sebagai pendingin panas yang dihasilkan oleh material 
uji saat gesekan. Spesimen yang digunakan adalah ball dengan material baja ST 70 dengan variasi pelumas pada disc. Dalam penelitian yang dilaksanakan, maka penyusun memberikan batasan, diantaranya yaitu kenaikan temperatur yang disebabkan oleh gesekan pin dan disc dianggap konstan. Menggunakan variasi pelumasan. Membahas tentang keausan pada disc, keausan pin diabaikan. Spesimen pengujian menggunakan pin dengan bentuk ball dan disc berbentuk plat datar. Dalam penelitian ini adapun tujuan yang ingin dicapai yaitu mengetahui faktor keausan pada disc dengan material ST 70 menggunakan tribotester pin-on-disc dengan variasi pelumas. Serta mengetahui lebar dan volume pada keausan.

\section{METODE PENELITIAN}

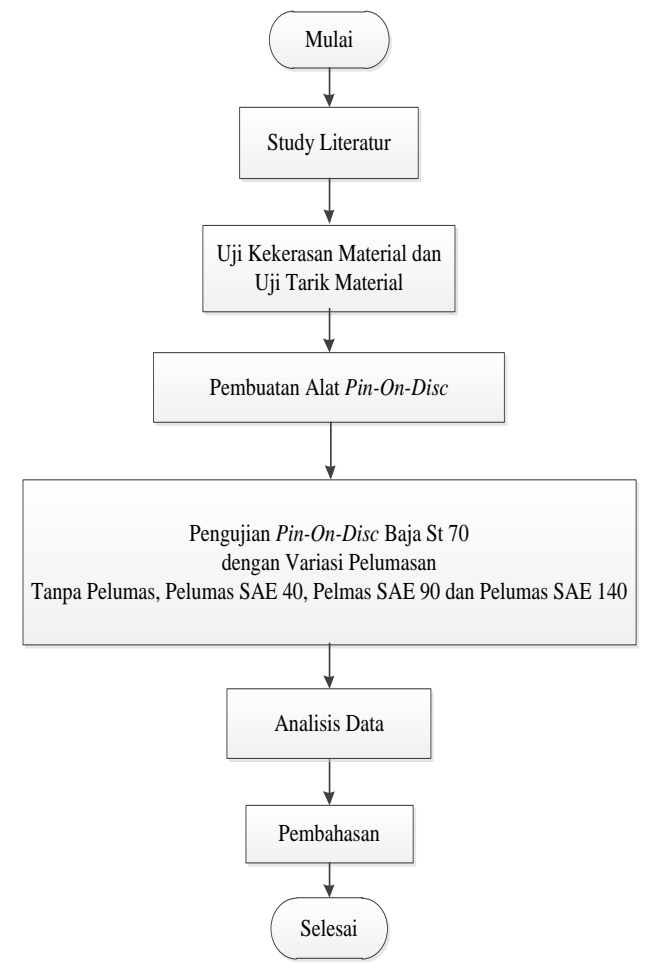

\section{Gambar 1. Diagram alir penelitian}

Metode atau cara yang digunakan dalam penelitian ini adalah dengan cara pengujian keausan disc baja St. 70 menggunakan alat tribotester pin-on-disc dengan variasi pelumasan dengan kecepatan putaran disc diatur menggunakan inverter dengan kecepatan putaran 90 RPM, dan beban pada pin $2 \mathrm{Kg}$. Pada penelitian ini menggunakan empat macam pengujian, yaitu tanpa pelumas, pelumas SAE 40, pelumas SAE 90 dan SAE 140. Pada pengujian tanpa pelumas pengambilan data dilakukan 15 menit sekali selama 3 kali, pengambilan data pada SAE 40,90 dan 140 dilakukan setiap 12 jam sekali selama 2 kali. Berikut diagram alir penelitian seperti terlihat pada gambar 1 .

\section{HASIL DAN PEMBAHASAN}

Adapun hasil pengujian analisis keausan disc dengan material baja St 70 menggunakan alat tribotester pin-on-disc dengan variasi pelumasan adalah sebagai berikut:

Tabel 1 Data pin dan disc ST. 70

\begin{tabular}{cccc}
\hline No. & & Nilai & Satuan \\
\hline 1. & Kekasaran Disc & 0,18 & $\mu \mathrm{m}$ \\
2. & Kekerasan baja & $97 / 20$ & $\mathrm{HRB} / \mathrm{HRC}$ \\
3. & Beban pengujian & 2 & $\mathrm{Kg}$ \\
4. & Yield stress & 552,504 & $\mathrm{MPa}$ \\
5. & Max. Stress & 719,359 & $\mathrm{MPa}$ \\
\hline
\end{tabular}

\section{Pengujian disc tanpa pelumasan}

Tabel 2 Hasil pengujian disc tanpa pelumas dengan putaran disc $64 \mathrm{rpm}$ dan radius jalur pakai $48,45 \mathrm{~mm}$.

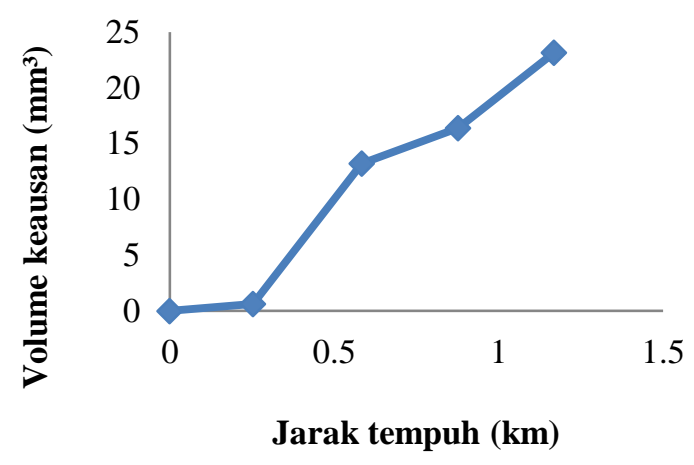

Gambar 2. keausan disc tanpa pelumas

Tabel 2 pengujian disc tanpa pelumasan

\begin{tabular}{ccccc}
\hline $\begin{array}{c}\text { Waktu } \\
(\mathbf{m e n i t})\end{array}$ & $\begin{array}{c}\text { Lebar } \\
\text { keausan } \\
(\mathbf{m m})\end{array}$ & $\begin{array}{c}\text { Volume } \\
\text { keausa } \\
\mathbf{n} \\
\left(\mathbf{m m}^{\mathbf{3}}\right)\end{array}$ & $\begin{array}{c}\text { Jarak } \\
\text { Tempuh } \\
(\mathbf{K m})\end{array}$ & $\begin{array}{c}\text { Faktor } \\
\text { Keausan } \\
\left(\mathbf{m m}^{3} / \mathbf{N} . \mathbf{m m}\right)\end{array}$ \\
\hline 13 & 0,5574 & 0,6273 & 0,2532 & $1,2643 \times{ }^{10-7}$ \\
30 & 1,5395 & 13,2146 & 0,5842 & $1,1542 \times 10^{-6}$ \\
45 & 1,6543 & 16,3989 & 0,8763 & $9,5481 \times 10^{-7}$ \\
60 & 1,8559 & 23,1521 & 1,1684 & $1,0109 \times 10^{-6}$ \\
\hline
\end{tabular}


Pada Gambar 2 Volume keausan paling besar yaitu berada pada jarak tempuh 1,1684 $\mathrm{km}$ dan nilai volume keausan $23,1521 \mathrm{~mm}^{3}$, dengan faktor keausan 8,1159 × $10^{-6}$ $\mathrm{mm}^{3} / \mathrm{N}$.mm, hal ini disebabkan karena semakin panjang jarak gesekannya maka semakin besar nilai volume keausan pada disc.

\section{Pengujian disc dengan pelumas SAE 40}

Tabel 3 Hasil pengujian disc pelumas SAE 40 dengan putaran disc $70 \mathrm{rpm}$ dan radius jalur pakai $27,85 \mathrm{~mm}$.

\section{Tabel 3 pengujian disc pelumas SAE 40}

\begin{tabular}{ccccc}
\hline $\begin{array}{c}\text { Waktu } \\
(\mathbf{j a m})\end{array}$ & $\begin{array}{c}\text { Lebar } \\
\text { keausan } \\
(\mathbf{m m})\end{array}$ & $\begin{array}{c}\text { Jarak } \\
\text { tempuh } \\
(\mathbf{k m})\end{array}$ & $\begin{array}{c}\text { Volume } \\
\text { keausan } \\
\left(\mathbf{m m}^{3}\right)\end{array}$ & $\begin{array}{c}\text { Faktor } \\
\text { Keausan } \\
\left(\mathbf{m m}^{3} / \mathbf{N} . \mathbf{m m}\right)\end{array}$ \\
\hline 24 & 0,4393 & 17,6298 & 0,1705 & $4,9323 \times 10^{-10}$ \\
36 & 0,5079 & 26,4446 & 0,2634 & $5,0817 \times 10^{-10}$ \\
48 & 0,5653 & 35,2595 & 0,3632 & $5,2549 \times 10^{-10}$ \\
\hline
\end{tabular}

Pada gambar 3 volume keausan paling besar yaitu berada pada jarak tempuh 35,2595 $\mathrm{km}$ dan nilai volume keausan $0,3632 \mathrm{~mm}^{3}$, dengan faktor keausan 5,0897 x $10^{-10}$ $\mathrm{mm}^{3} / \mathrm{N}$.mm, hal ini disebabkan karena semakin jauh jarak gesekannya maka semakin besar nilai volume keausan pada disc.

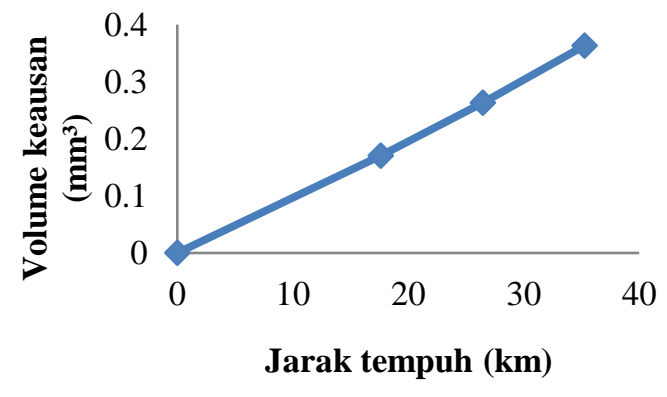

\section{Gambar 3. disc dengan pelumas SAE 40}

\section{Pengujian disc dengan pelumas SAE 90}

Tabel 4 Hasil pengujian disc pelumas SAE 90 dengan putaran disc $67 \mathrm{rpm}$ dan radius jalur pakai $33,95 \mathrm{~mm}$.

\section{Tabel 4 pengujian disc dengan SAE 90}

\begin{tabular}{ccccc}
\hline $\begin{array}{c}\text { Waktu } \\
(\mathbf{j a m})\end{array}$ & $\begin{array}{c}\text { Lebar } \\
\text { keausan } \\
(\mathbf{m m})\end{array}$ & $\begin{array}{c}\text { Jarak } \\
\text { tempuh } \\
(\mathbf{k m})\end{array}$ & $\begin{array}{c}\text { Volume } \\
\text { keausan } \\
\left(\mathbf{m m}^{3}\right)\end{array}$ & $\begin{array}{c}\text { Faktor } \\
\text { Keausan } \\
\left(\mathbf{m m}^{3} / \mathbf{N} \cdot \mathbf{m m}\right)\end{array}$ \\
\hline 28 & 0,3908 & 23,9985 & 0,1463 & $3,1096 \times 10^{-10}$ \\
40 & 0,5322 & 34,2836 & 0,3695 & $5,4975 \times 10^{-10}$ \\
52 & 0,5484 & 44,5686 & 0,4042 & $4,6269 \times 10^{-10}$ \\
\hline
\end{tabular}

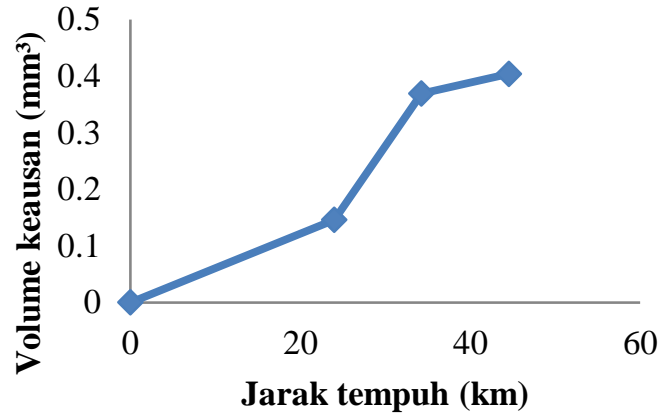

Gambar 4. Grafik hasil pengujian keausan disc dengan pelumas SAE 90

Pada gambar 4 volume keausan paling besar yaitu berada pada jarak tempuh 44,5686 $\mathrm{km}$ dan nilai volume keausan $0,4042 \mathrm{~mm}^{3}$, dengan faktor keausan 4,4114 x $10^{-10}$ $\mathrm{mm}^{3} / \mathrm{N}$.mm, hal ini disebabkan karena semakin jauh jarak gesekannya maka semakin besar nilai volume keausan pada disc.

\section{Pengujian disc dengan pelumas SAE 140}

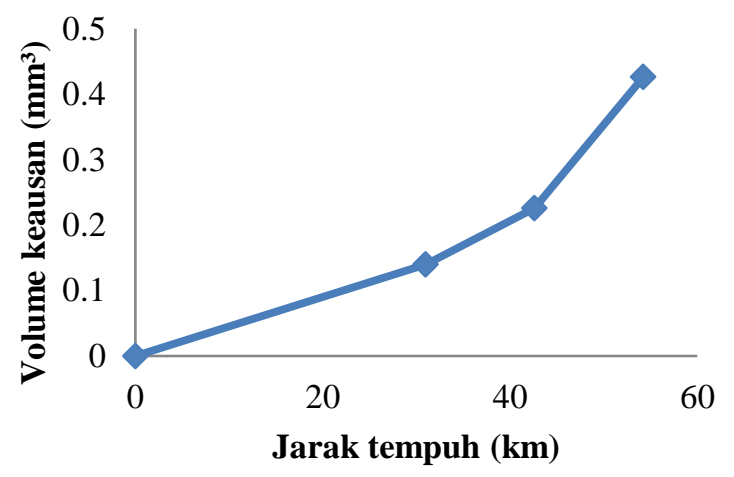

Gambar 5. keausan disc pelumas SAE 140

Tabel 5 Hasil pengujian disc pelumas SAE140 dengan putaran disc $65 \mathrm{rpm}$ dan radius jalur pakai $39,55 \mathrm{~mm}$.

\begin{tabular}{ccccc}
\multicolumn{6}{c}{ Tabel 5 hasil pengujian disc pelumas SAE 140 } \\
\hline $\begin{array}{c}\text { Waktu } \\
(\text { jam })\end{array}$ & $\begin{array}{c}\text { Lebar } \\
\text { keausan } \\
(\mathbf{m m})\end{array}$ & $\begin{array}{c}\text { Jarak } \\
\text { tempuh } \\
(\mathbf{k m})\end{array}$ & $\begin{array}{c}\text { Volume } \\
\text { keausan } \\
\left(\mathbf{m m}^{3}\right)\end{array}$ & $\begin{array}{c}\text { Faktor } \\
\text { Keausan } \\
\left(\mathbf{m m}^{3} / \mathbf{N} . \mathbf{m m}\right)\end{array}$ \\
\hline 32 & 0,366 & 30,9971 & 0,1399 & $2,3039 \times 10^{-10}$ \\
44 & 0,4291 & 42,6209 & 0,2256 & $2,7002 \times 10^{-10}$ \\
56 & 0,5305 & 54,2449 & 0,4263 & $4,0089 \times 10^{-10}$ \\
\hline
\end{tabular}

Gambar 5 volume keausan paling besar yaitu berada pada jarak tempuh $54,2449 \mathrm{~km}$ dan nilai volume keausan $0,4263 \mathrm{~mm}^{3}$, dengan 
faktor keausan 3,0044E-10 mm³/N.mm, hal ini dikarenakan semakin jauh jarak gesekannya maka semakin besar nilai volume keausan pada disc.

\section{Pembahasan Hasil Pengujian}

Setelah melakukan pengujian dan dilakukan analisis pada masing-masing kondisi pelumasan, maka didapatkan hasil sebagai berikut:

\section{Volume Keausan pada disc}

Pada gambar 6 menunjukkan bahwa pada pengujian tanpa pelumas memiliki nilai volume keausan yang paling tinggi, yaitu $23,1521 \mathrm{~mm}^{3}$, hal ini dikarenakan pin dan disc mengalami kontak secara langsung. Pada kondisi menggunakan pelumas, kontak yang terjadi pada pin dan disc dipengaruhi oleh nilai viskositas pelumas. Apabila nilai viskositas atau kekentalan pelumas yang digunakan semakin tinggi maka volume keausan semakin kecil.

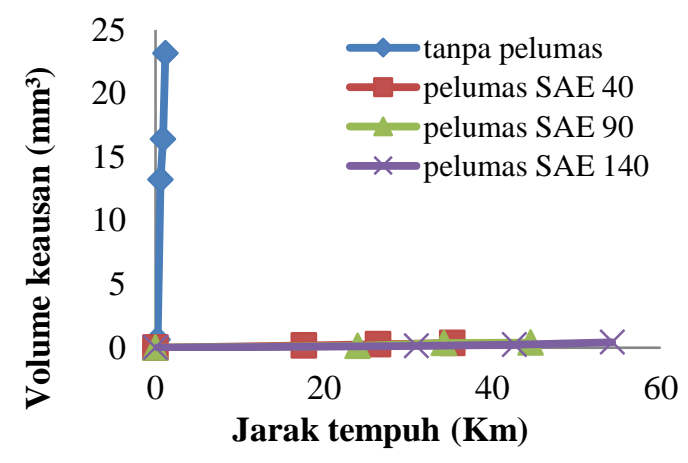

\section{Gambar 6. Grafik hubungan volume keausan disc dengan jarak tempuh}

Hal ini disebabkan oleh kekasaran permukaan pada disc, karena pelumas dapat masuk ke dalam celah dan mengendap di dasar, sehingga mempengaruhi gesekan yang terjadi antara pin dan disc.

Pada kondisi pelumasan volume keausan yang terjadi pada disc mengalami perubahan, hal ini disebabkan karena pin dan disc di separasi/dilapisi lapisan film pelumas, semakin tinggi nilai viskositas/kekentalan pelumas maka nilai volume keausannya semakin kecil, yang membedakannya adalah jarak tempuh yang diperlukan untuk masingmasing jenis pelumas. Pada pengujian yang dilakukan menggunakan pelumas dengan grade SAE 40, SAE 90 dan SAE 140.

\section{Tabel 6 Faktor Keausan Disc}

\begin{tabular}{cc}
\hline Kondisi Pengujian & $\begin{array}{c}\text { Rata-rata Faktor } \\
\text { keausan }\left(\mathbf{m m}^{3} / \mathbf{N} . \mathbf{m m}\right)\end{array}$ \\
\hline Tanpa Pelumas & $8,1159 \times 10^{-6}$ \\
Pelumas SAE 40 & $5,0897 \times 10^{-10}$ \\
Pelumas SAE 90 & $4,4114 \times 10^{-10}$ \\
Pelumas SAE 140 & $3,0044 \times 10^{-10}$ \\
\hline
\end{tabular}

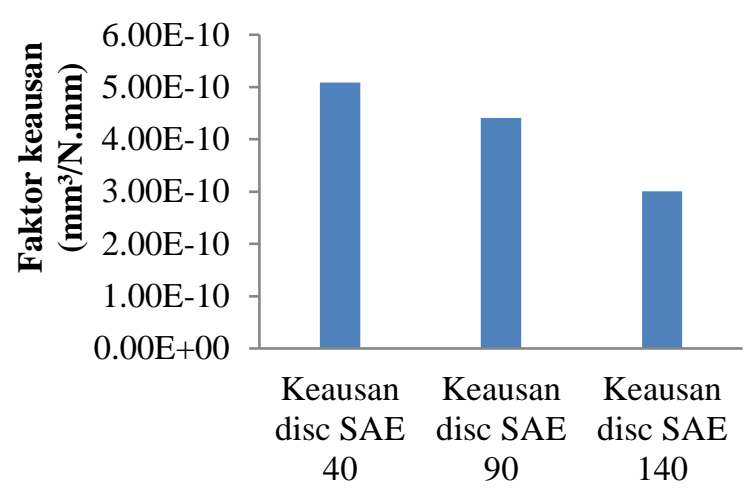

\section{Gambar 7. Faktor keausan pelumasan}

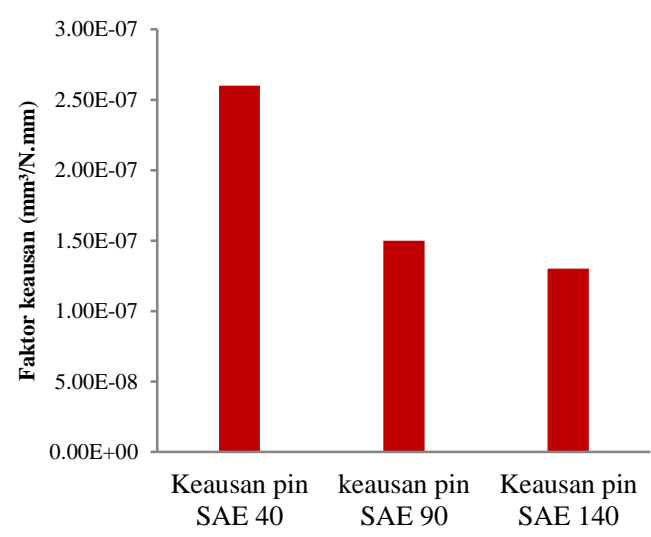

\section{Gambar 8. Faktor keausan yang terjadi pada disc dengan kondisi pelumasan}

Berdasarkan pada Gambar 7 dan 8 Terlihat bahwa nilai dari faktor keausan yang terjadi pada kondisi pelumasan mengalami perubahan, dikarenakan kontak yang terjadi pada pin dan disc dipengaruhi oleh nilai viskositas pelumas. Apabila nilai viskositas atau kekentalan pelumas yang digunakan semakin tinggi maka faktor keausan semakin kecil, hal ini dikarenakan kontak yang terjadi 
pada pin dan disc di separasi/dilapisi lapisan film pelumas.

Jika dibandingkan dengan nilai faktor keausan pin yang sudah dilakukan penelitian oleh (Afta dkk., 2018), faktor keausan disc lebih kecil dari nilai faktor keausan pin, hal ini dikarenakan pin mengalami gesekan penuh selama satu putaran atau $360^{\circ}$, sedangkan disc hanya menerima gesekan sekali setiap putaran $1: 360^{\circ}$.

\section{Hasil Foto mikro}

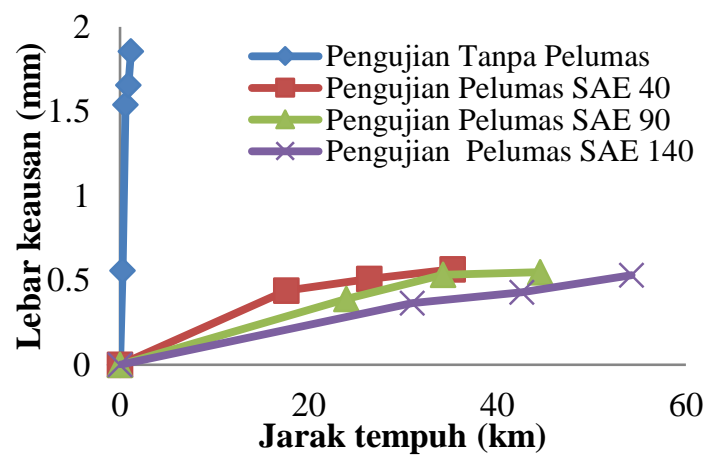

Gambar 9. keausan pin kondisi pelumasan

Pada Gambar 9 menunjukkan hasil dari analisis foto mikro dengan pembesaran 50 kali. Gambar tersebut menunjukkan bahwa kondisi tanpa pelumas lebar keausannya paling tinggi, karena pengujian tanpa pelumas pin dan disc terjadi kontak secara langsung tanpa adanya pembatas.

Berbeda dengan kondisi pelumasan, lebar keausan yang terjadi lebih kecil, karena hal ini dipengaruhi oleh adanya pelumas pada saat pin dan disc terjadi kontak/bergesekan. Semakin tinggi nilai viskositas pelumasan, maka lebar keausan akan semakin kecil.

\section{PENUTUP}

\section{Kesimpulan}

Adapun hasil pembahasan analisis keausan disc dengan material baja St 70 menggunakan alat tribotester pin-on-disc dengan variasi pelumasan dapat disimpulkan bahwa:

1. Faktor keausan yang paling tinggi terletak pada pengujian tanpa pelumas dengan nilai faktor keausan 8,1159 × $10^{-7}$ $\mathrm{mm}^{3} / \mathrm{N} . \mathrm{mm}$. sedangkan nilai faktor keausan yang menggunakan pelumas
SAE 40 adalah $5,0897 \times 10^{-10} \mathrm{~mm}^{3} / \mathrm{N} \cdot \mathrm{mm}$, pelumas SAE 90 adalah $4,4114 \times 10^{-10}$ $\mathrm{mm}^{3} / \mathrm{N} . \mathrm{mm}$ dan pelumas SAE 140 adalah $3,0044 \times 10^{-10} \mathrm{~mm}^{3} /$ N.mm. Semakin tinggi nilai viskositas atau kekentalan dari pelumas yang digunakan maka faktor keausannya akan semakin kecil.

2. Berdasarkan foto mikro, semakin jauh waktu pengujian maka semakin lebar keausan disc. Tetapi Semakin tinggi nilai viskositas atau kekentalan dari pelumas yang digunakan maka lebar keausannya akan semakin kecil.

3. Pengujian yang nilai volume keausannya paling tinggi terletak pada pengujian tanpa pelumas dengan nilai volume keausan 23,1521 $\mathrm{mm}^{3}$, sedangkan pengujian yang menggunakan variasi jenis pelumas SAE 40, pelumas SAE 90 dan pelumas SAE 140 mengalami perubahan dikarenakan kontak yang terjadi pada pin dan disc dipengaruhi oleh nilai viskositas/kekentalan pelumas.

\section{DAFTAR PUSTAKA}

Afta, A. B., Darmanto, D., \& Syafa'at, I. (2018). ANALISIS KEAUSAN BALL BAJA ST 90 MENGGUNAKAN TRIBOTESTER PIN-ON-DISC DENGAN VARIASI KONDISI PELUMAS. CENDEKIA .... https://publikasiilmiah.unwahas.ac.id/ind ex.php/CE/article/download/2083/2103

Armanto, E., Burhanudin, A., \& ... (2012). Perancangan mesin uji tribologi pin-ondisc. Prosiding SNST .... https://publikasiilmiah.unwahas.ac.id/ind ex.php/PROSIDING_SNST_FT/article/v iew/65/63

Firmansyah. (2010). Firmansyah: TRIBOLOGY SYSTEM. http://redyfirmansyah.blogspot.com/201 0/03/tribology-system.html

Prabowo, D., Burhanudin, A., \& ... (2012). RANCANG BANGUN DAN PENGUJIAN PEMANAS PADA DISC UNTUK ALAT UJI TRIBOMETER TIPE PIN-ON-DISC. Prosiding SNST .... https://publikasiilmiah.unwahas.ac.id/ind ex.php/PROSIDING_SNST_FT/article/v iew/63/61 